\title{
Effect of Temperature on the Wear Properties of Alloy Steel under Jatropha Curcas Biodiesel
}

\author{
N. A. Shaufe ${ }^{a}$, M. A. Maleque ${ }^{a}$, A. A Saleh ${ }^{b}$ and P. Paruka ${ }^{c}$ \\ ${ }^{a}$ Manufacturing and Materials Department, Faculty of Engineering, International Islamic University \\ Malaysia , Kuala Lumpur 53100, Malaysia \\ ${ }^{\mathrm{b}}$ Mechanical Engineering Department, University Malaysia Sarawak, Sarawak 94300, Malaysia \\ 'Department of Mechanical Engineering, Politeknik Kota Kinabalu, 88450, Sabah, Malaysia \\ Email: maleque@iium.edu.my; ainshaufe@iium.edu.my
}

Keywords: Jatropha curcas biodiesel; alloy steel; wear; surface profilometry.

\begin{abstract}
This paper presents the effect of Jatropha curcas biodiesel on the wear properties of mild steel, which was coated by preplacement of TiC particulate and melting it using a conventional TIG torch arc heat source. The aim of the study is to investigate the wear behaviour of surface modified AISI 4340 steel and the uncoated AISI 4340 steel which were performed using CSM tribometer at four different temperatures viz., $100{ }^{\circ} \mathrm{C}, 120^{\circ} \mathrm{C}, 140{ }^{\circ} \mathrm{C}$, and $160^{\circ} \mathrm{C}$, with the presence of jatropha biodiesel. At the end of the tests, wear characteristics was investigated by weight loss measurements and changes of the exposed metal surface. Surface morphology was examined by scanning electron microscope and surface profilometry. EDX analysis was performed on the samples' surface. Results showed that wear of alloy steel increases with increasing temperature. TiC coated alloy steel showed improved wear resistance as this alloy steel demonstrated lower wear volume loss as compared to the uncoated steel in presence of jatropha biodiesel at higher temperature.
\end{abstract}

\section{Introduction}

Due to the depletion of the traditional petroleum reservoirs and its negative impact on ecological systems, the demand for clean, green, reliable, and renewable source of energy has been increasing. Biodiesel is a domestically produced, renewable fuel that can be manufactured from vegetable oils, animal fats, or recycled restaurant grease for use in diesel vehicles [1-4]. Biodiesel's physical properties are similar to those of petroleum diesel, but it is a cleaner-burning alternative. Using biodiesel in place of petroleum diesel, especially in older vehicles, can reduce emissions [5]. Biodiesel has a number of advantages as compared to the conventional petroleum diesel, i.e. reduced toxicity, reduction of exhaust emissions and biodegradability, derivation from a renewable feedstock, and domestic origin [6]. It can be used in diesel engine with little or no modification. Although biodiesel has been acknowledged as an alternative fuel, there are some significant disadvantages which limit its commercial applications. These include oxidation instability as a consequence of changing temperature, exposure to air, lower volatility, moisture absorption, and reactivity of unsaturated hydrocarbon chains [7]. These characteristics of biodiesel are more prone to influence the lubrication parameters, friction, and wear of engine components.

The wear performance of biodiesel is crucial for its application in automobiles [7]. Most of the automotive materials are commonly made from mild steel. Therefore, it is important to investigate the wear properties of steel in biodiesel. In this study, effect of temperature on the wear properties of the uncoated and TiC-coated AISI 4340 steel in the presence of jatropha biodiesel was investigated using CSM tribometer. Surface morphology was examined by scanning electron microscope with integrated EDX analyzer.

\section{Experimental Procedure}

The jatropha biodiesel was used in this work supplied by Biofuel Bionas Sdn.Bhd. The material that is being used as a substrate material is AISI $4340(37 \mathrm{~mm} \times 11 \mathrm{~mm} \times 5 \mathrm{~mm})$ alloy steel. The sources of the raw materials and the chemical composition of the sample have been given elsewhere [8]. This low alloy steel was surface modified using preplaced powder of TiC on the surface of AISI 